\title{
The Serendipitous Discovery of a Rose Odorant
}

\author{
Nicole Hauser ${ }^{\S a}$, Philip Kraft ${ }^{\mathrm{b}}$, and Erick M. Carreira ${ }^{\star a}$ \\ §SCS-Metrohm Award for the Best Oral Presentation in Organic Chemistry
}

\begin{abstract}
Serendipity has played a role in many groundbreaking scientific discoveries. Key to their identification and exploitation is the ability to recognize the unexpected and invest time trying to understand it. Like any other field of scientific research, total synthesis requires determination and perseverance. When the first-generation route towards a target compound fails, new approaches are developed based on insights gained in the initial studies. Careful analysis of data obtained in a 'failed' approach, e.g. when a reaction did not yield the desired or any expected outcome, can lead to spectacularly improved routes and discoveries that have impact beyond the synthesis of the selected target compound. Serendipity has further led to the identification of intriguing properties that materials or single molecules have, as exemplified by the discovery of electrically conductive polymers. During our total synthesis endeavors towards a complex natural product, we identified a small molecule with interesting olfactory properties, which we decided to investigate further.
\end{abstract}

Keywords: Bioactivity $\cdot$ Rose odorant $\cdot$ Total synthesis $\cdot$ Serendipity

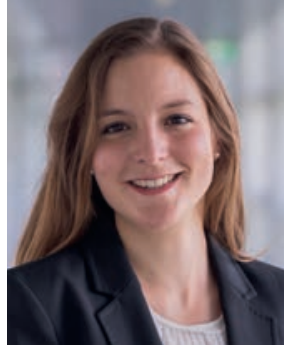

Nicole Hauser obtained her Bachelor's and Master's degrees in chemistry from ETH Zürich. After an internship at F. HoffmannLa Roche in Basel, she pursued her PhD in the group of Prof. Erick M. Carreira at ETH Zürich focusing on the total synthesis of complex natural products. She obtained her $\mathrm{PhD}$ in November 2019 and will continue her scientific career as a SNSF postdoctoral fellow in the group of Prof. Mohammad R. Seyedsayamdost at Princeton University in the field of antibiotics research.

\section{Introduction}

The purpose of total synthesis has shifted since the early days of the field. [1] Initially, natural products were synthesized via known transformations in order to confirm or help elucidate their structure. In addition, a significant part of the analytics consisted in the derivatization of novel compounds via known chemical reactions in order to obtain a fully characterized reference substance. However, significant progress in analytical methods has rendered synthesis less important for structure elucidation and at the same time also allowed to conduct reactions on smaller scale. Knowledge of the structure of complex target molecules at the outset of total synthesis projects, along with the time that was gained with improved analytical methods, inspired the field of synthetic methods development. Furthermore, when discussing the value of total synthesis after the advent of X-ray crystallography and NMR spectroscopy, R. B. Woodward stated in his landmark publication on the total synthesis of strychnine " $[\ldots] \mathrm{Of}$ course, men make much use of excuses for activities which lead to discovery, and the lure of unknown structures has in the past yielded a huge dividend of unsought fact, which has been of major importance in building organic chemistry as a science. Should a surrogate now be needed, we do not hesitate to advocate the case for synthesis."'[2]

\section{The Serendipitous Discovery of a Novel Odorant}

Our group is involved in the total synthesis of complex natural products with interesting molecular scaffolds ${ }^{[3]}$ or bioactivities. ${ }^{[4]}$ Involved in an exciting total synthesis project, we realized that an early intermediate in the first-generation route exhibited a pleasant smell reminiscent of rose. ${ }^{[5]}$ Closer investigation in collaboration with $\mathrm{P}$. Kraft from Givaudan revealed that our synthetic intermediate 1 showed a rare feature in that both the quantity and the quality of the odor perception varied among two groups of panelists that were involved in its assessment (Fig. 1A).

To the two thirds of hyposmic panelists bifunctional 2,2-bis(prenyl)-3-oxobutyronitrile (1) smelled weakly like rose, with an odor threshold of $19 \mathrm{ng} / \mathrm{L}$ air. The remaining third panelists, which constituted a hyperosmic group, described the odor as strong, ivy and green with an odor threshold of $0.25 \mathrm{ng} / \mathrm{L}$ air. This finding is intriguing because there are only few examples of fragrance molecules that evoke disparate odor impressions in different test subjects. More frequently, the detection threshold varies
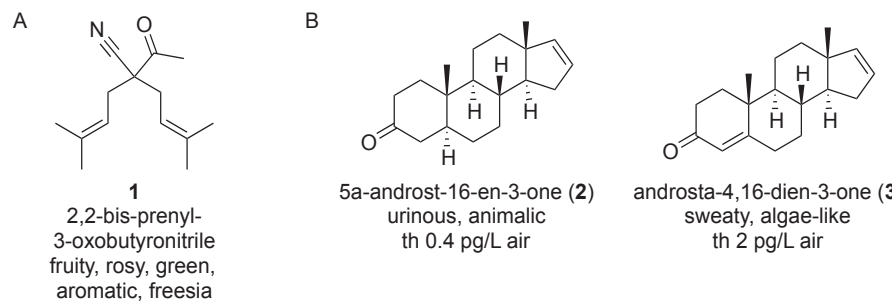
urinous, animalic

androsta-4,16-dien-3-one (3) th $2 \mathrm{pg} / \mathrm{L}$ air

Fig. 1. A) Serendipitously discovered odorant 1. B) The quantitative and qualitative olfactory perception of $\mathbf{2}$ and $\mathbf{3}$ is affected by two amino acid changes in the olfactory receptor binding pocket. 
among panelists up to the extreme case of specific anosmia, where some people cannot detect the smell of an odorant. Significant differences in odor detection have been reported for some steroid-type odorants. The olfactory perception of $5 \alpha$-androst-16en-3-one (2), ${ }^{[6]}$ the odor threshold of which is among the lowest ones known, and androsta-4,16-dien-3-one (3) ${ }^{[7]}$ are affected by two point mutations in the genes encoding the human odorant receptor OR7D4 (Fig. 1B). ${ }^{[8]}$ The two non-synonymous polymorphisms lead to amino acid changes R88W and T133M. The most common allele is therefore referred to as RT, and the other as WM. While OR7D4 RT selectively responded to androstenone and androstadienone, OR7D4 WM did not respond to any of the stimuli at concentrations of up to $10^{-5} \mathrm{M}$. Analysis of the odor perception as a function of genotype revealed that people with RT/WM described the odors of androstenone and androstadienone as less intense compared to the RT/RT genotype, an effect that was confirmed by quantitative odor threshold determination. Regarding odor quality, the RT/WM group of subjects rated the two steroidal odorants as less unpleasant than the RT/RT group. These insights are especially valuable with respect to the complexity of the sense of smell in humans and the question regarding human pheromones that came up with the discovery of steroid-type odorants by Prelog and Ružička. ${ }^{[9]}$

\section{Rose Odorants}

Along with jasmine and lily-of-the-valley (muguet), rose is a major ingredient in perfumery products. ${ }^{[10]}$ The natural and synthetic rose odorants display multifaceted side aspects, suggestive of room for novel odorants. For example, our lead compound retained a green note along with the dominating rose character. The sense of smell is very complex, and odor detection occurs by a combinatorial recognition pattern created by the simultaneous activation of several structurally diverse receptors with various affinities. ${ }^{[11]}$ Therefore, empirical rules were developed to help the design of novel odorants. According to the rose odorant rule proposed by Hamannuns Boelens in 1973, the osmophoric group should generally be a hydrogen bond donor such as a hydroxy group (Fig. 2).[10b,12] However, sometimes ether or oxycarbonyl also work. The $\beta$-carbon was suggested to be substituted with $\alpha$-branched, unsaturated or aromatic $\mathrm{C}_{7}-\mathrm{C}_{9}$ moiety, and further substitution at that position is tolerated. While Boelens' rule holds true for some important examples of both natural and synthetic rose odorants such as citronellol (4), 2-phenylethanol (5) and Phenoxanol (6), the design of rose odorants remains challenging.

Modern computational methods are used to generate quantitative olfactophore models based on the structures of odorants with desired olfactory properties. In analogy to pharmacophore models, olfactophore models visualize osmophoric groups and hydrophobic moieties in their three-dimensional arrangement. As such, they provide information about the geometry of receptor binding pockets and types of interaction that molecules with certain olfactory properties undergo, correlated with the activity of a compound. Despite significant progress in computational modeling there is still no general olfactophore model for rose odorants. This is partially due to the stability and wide availability of various rose fragrances but also due to their conformational flexibility. ${ }^{[10 b]}$ One of the most successful functional rose odorants was Rosacetol

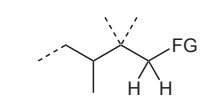

Schematic representation of Boelens' empirical rose rules

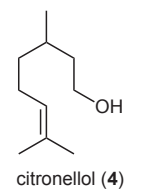

citronellol $(4)$
rosy, floral

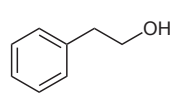

2-phenylethanol (5) rosy, floral, bread

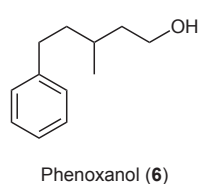

rosy, floral, metallic
Fig. 2. Visualization of Boelens' empirical rule for rose odorants and examples of fragrance molecules that obey it.
(7), ${ }^{[13]}$ which lacks structural resemblance with other well-known rose odorants and at the same time stands out in that structurally related molecules do not possess interesting olfactory properties (Fig. 3). Due to its detrimental environmental effect, ${ }^{[14]}$ extensive research for a replacement was initiated in the 1990s, which led to the identification of Peonile (8) ${ }^{[15]}$ and Petalia $(\mathbf{9})^{[16]}$ as powerful rose odorants. They exhibit a rosy, floral-green, powdery smell at an odor threshold of $0.60 \mathrm{ng} / \mathrm{L}$ air, respectively a rosy-fruity, lychee, powdery smell $0.11 \mathrm{ng} / \mathrm{L}$ air and bear a nitrile function as the osmophore. Nitrile groups display extraordinary chemical stability and have thus been used to substitute aldehydes to widen the application spectrum of fragrance molecules, however, they are often associated with a harsh, metallic smell.[17]

In addition to a nitrile moiety $\mathbf{1}$ bears a methyl ketone and is thus bifunctional, which is uncommon among known rose odorants. In many cases, the presence of more than one polar group results in a decrease of odor strength or total loss thereof. However, bifunctional odorants are known for example in the family of lilyof-the-valley odorants. They often display a defined distance relationship of a hydrogen bond donor and a hydrogen bond acceptor moiety to form an intramolecular hydrogen bond. ${ }^{[18]}$ In the case of our lead compound, both the nitrile and the ketone could potentially act as osmophoric groups. Indeed, this bifunctionality could explain the difference in odor perception among the panelists, e.g. small variations in the structure of the receptor binding pocket could favor either the methyl ketone to undergo hydrogen bonding interactions, or the nitrile moiety.

\section{The Discovery, Design and Development of Novel Odorants}

The fragrance industry is situated between the pharmaceutical industry and the petrochemical industry regarding production volume and price of products. ${ }^{[10 \mathrm{a}, 19]}$ The extraction of some odorants such as musks from natural sources is extremely arduous, expensive, and in some cases morally questionable. This leads fragrance and flavor companies to search for analogs with similar olfactory properties at lower production or isolation cost. Like in other fields of research, some important findings with long-lasting impact arose by serendipity. The first nitro musk analog, Musk Baur (10), ${ }^{[20]}$ was discovered accidentally and lacks any structural resemblance with other musk odorants known at the time (Fig. 4). Albert Baur was investigating the synthesis of explosives, when he noticed a strong musky smell. Structural modifications then led to the discovery of Musk Ketone (11), ${ }^{[21]}$ which has been among the most successful musky odorants due to its low odor threshold of $0.1 \mathrm{ng} / \mathrm{L}$ and low cost.
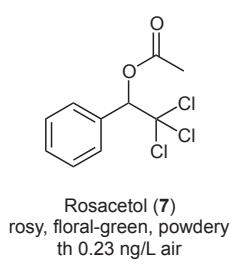
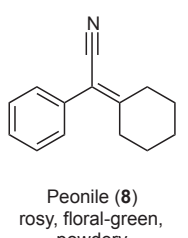

powdery

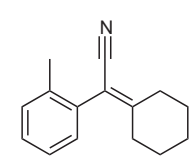

Petalia (9) rosy-fruity, lychee, th $0.11 \mathrm{ng} / \mathrm{L}$ air
Fig. 3. Extensive research to replace Rosacetol (7) led to the discovery of Peonile (8) and Petalia (9).

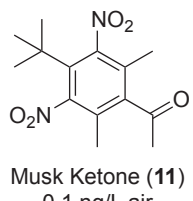

$0.1 \mathrm{ng} / \mathrm{L}$ air

Fig. 4. Serendipitously discovered Musk Baur (10) was the basis for the development of one of the most successful musk odorants, Musk Ketone (11). 
A common strategy to design and develop novel fragrances is to modify the natural substance or congeners in order to obtain compounds that can be accessed more easily and/or efficiently but display similar olfactory properties. Supported by olfactophore modeling, structure-odor relationship studies are undertaken according to empirical analogies and intuition employing synthetic tailoring strategies. This procedure is analogous to medicinal chemistry research. In several instances, intermediates in syntheses of targeted fragrance molecules were found to be powerful odorants. For example Moxalone (12), ${ }^{[22]}$ an intermediate towards 13 was the most potent musky odorant discovered when exploring the chemical and olfactory space around Klausenone (14) ${ }^{[23]}$ (Fig. 5). Similarly, Habanolide (15) ${ }^{[24]}$ is unsaturated Exaltolide (16) $)^{[25]}$ and a late-stage intermediate in a synthetic approach to $\mathbf{1 6}$.

These examples emphasize an important difference between odor and other bioactivities: the synthetic chemist can, to some extent, evaluate odor by themselves without a time delay, while the evaluation of other bioactivities is usually more laborious and time-consuming. When working on the total synthesis of a bioactive target molecule with unknown mode of action, it is worth reflecting that intermediates resembling the natural product can potentially also display the desired bioactivity. In fact, in medicinal chemistry so-called privileged scaffolds are exploited and divergently decorated in order to tune their pharmacological properties. ${ }^{[26]}$ Along the same lines, a large part of antibiotics on the market are synthetically tailored versions of four classes of antibacterial agents discovered between the 1930s and the 1960s.[27]

When exploring the chemical space around bioactive compounds, structural simplicity and ease of access are of great advantage. The synthesis of 2,2-bis(prenyl)-3-oxobutyronitrile (1) was accomplished in two steps by deprotonation of 5-methylisoxazole (17) with sodium hydride and subsequent double prenylation of $\mathbf{1 8}$, which encouraged the systematic investigation of the structure-odor relationship around our serendipitously found bifunctional odorant (Scheme 1).

\section{Structure-Odor Relationship Studies}

Guided by the structural and olfactory resemblance of our lead compound 1 with Givaudan's Peonile (8) and Petalia (9), the first compound we synthesized combined the structural elements

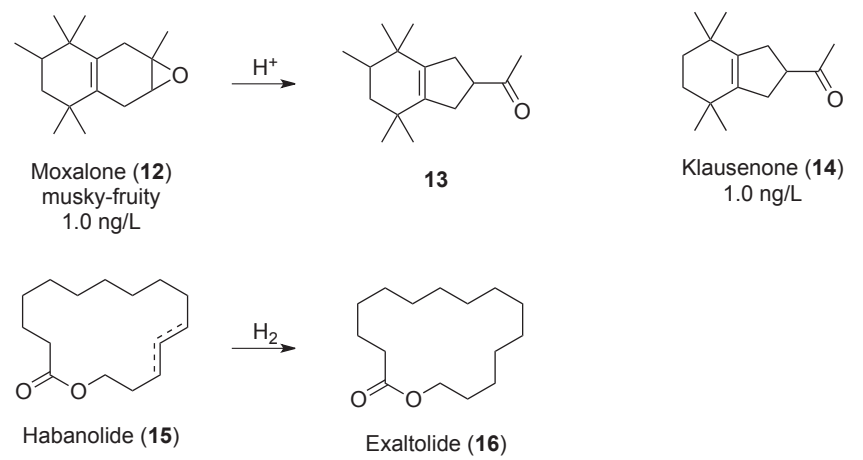

Fig. 5. Late-stage synthetic intermediates Moxalone (12) and Habanolide (15) in the exploration of chemical space around Klausenone (14) and in an efficient route to Exaltolide (16), respectively.

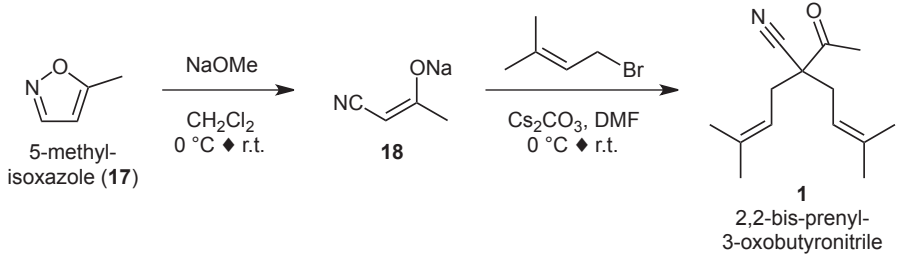

Scheme. 1. Two-step synthesis of ketonitrile 1 from 5-methylisoxazole (17) via sodium enolate 18. of Peonile (8) and our lead compound (1). The installation of a methyl ketone on the molecular scaffold of Peonile (8) to give 19, however, led to almost complete loss of odor (Fig. 6). Following the principles of synthetic tailoring, the ketone functionality was replaced by an aldehyde and carboxylic esters. Replacement of the prenyl substituents by other hydrophobic moieties such as allyl, benzyl, cis-crotyl, alkynyl, and cyclopropylmethyl completed our small library of congeners. In the course of our studies we thus discovered three additional compounds that were detected at different odor thresholds by two groups of panelists: methylene analog 20, bis-allyl methyl ketone 21 and bis-alkynylated methyl ester 22.

Additionally, bifunctional bis-prenylated methyl ester $\mathbf{2 3}$ was identified as a powerful odorant with an odor threshold of $0.38 \mathrm{ng} / \mathrm{L}$ air and a uniform floral rosy smell reminiscent of linalyl esters, chamomile (Fig. 7). The olfactory space around our lead compound was found to be extremely narrow. For example, the application of the isobutenyl-phenyl analogy experimentally found by Sturm ${ }^{28]}$ led to completely odorless $\mathbf{2 4}$. Similarly, bis-demethyl seco-analog $\mathbf{2 5}$ of our most potent odorant $\mathbf{2 3}$ was odorless. With the data set obtained in this study, attempts were directed at elucidating the receptor binding of 2,2-bis(prenyl)3-oxobutyronitrile (1) and congeners.

Methylene analog 20 can only bind via the nitrile function to the receptors' hydrogen bonding moiety. The rosy smell of the lead compound was retained in $\mathbf{2 0}$ and the detection threshold was low for hyperosmics, which suggested that the nitrile moiety dominates the hydrogen-bonding interaction. In order to evaluate this hypothesis, P. Kraft created an olfactophore model using the Discovery Studio 18.1.100.18065 software package. ${ }^{[29]}$ The study was based on a training set encompassing 12 nitrile rose odorants with odor thresholds of up to $500 \mathrm{ng} / \mathrm{L}$ air (Table 1). In addition to nine compounds that emerged from this study, of which three each were active $(\mathbf{1}, \mathbf{2 0}, \mathbf{2 3})$, moderately active $(\mathbf{2 6}, \mathbf{2 7}, \mathbf{2 8})$ and inactive $(\mathbf{1 9}$, 29, 30), Rosacetol (7), Peonile (8) and Petalia (9) were considered.

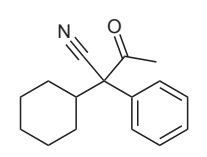

19

vague, green

rosy, leathery
th $500 \mathrm{ng} / \mathrm{L}$ air

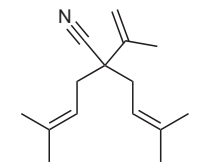

20

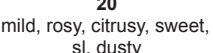

$\mathrm{sl}$. dusty
th $0.40 \mathrm{ng} / \mathrm{L} / 125 \mathrm{ng} / \mathrm{L}$

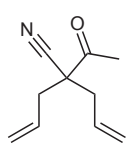

21

metallic, conif

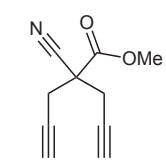

22
Fig. 6. The synthesis of ketonitrile 19 was inspired by the structural and olfactory similarity of $\mathbf{1}$ with Peonile (8). Synthetic tailoring approaches yielded 20, 21 and 22, which all exhibited disparate detection thresholds in different people.

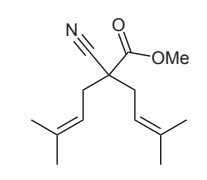

23
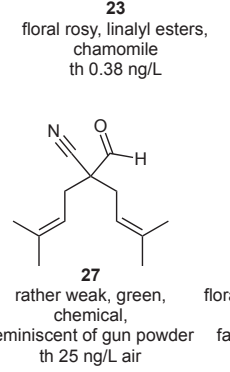

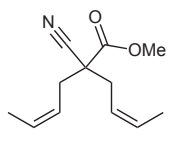

25
odorless

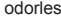

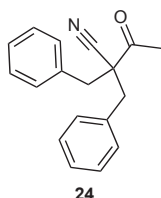

24

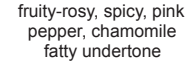

pepper, chamomile fatty undertone
th $3.8 \mathrm{ng} / \mathrm{L}$ air
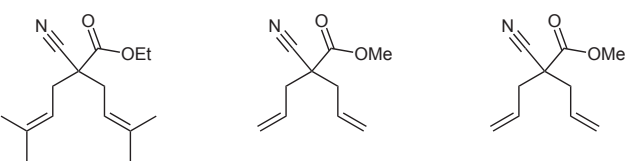

-fruity, aromatic, arnic

teses, osmanthus

th $8.3 \mathrm{ng} / \mathrm{L}$ air

Fig. 7. Nitrile rose odorants from our library. Benzylated ketonitrile 24 and seco compound 25 to our surprise were odorless. Compounds $\mathbf{2 3}$, $\mathbf{2 6}, \mathbf{2 7}, \mathbf{2 8}, \mathbf{2 9}, \mathbf{3 0}$ were included in the training set for olfactophore modeling. 


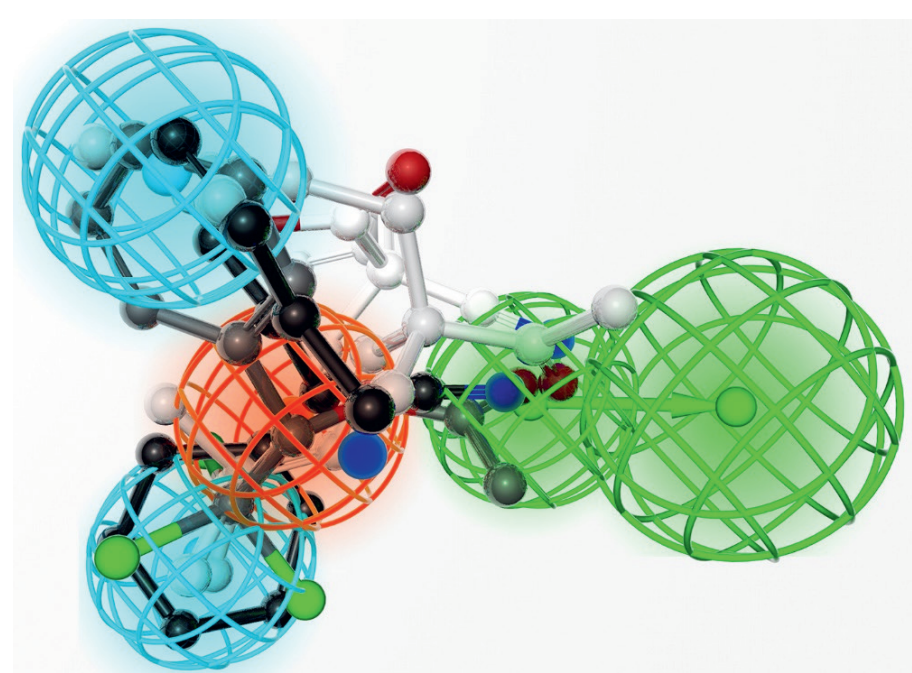

Fig. 8. Olfactophore model for nitrile rose odorants with Petalia (9, black), Rosacetol (7, dark grey), the ketonitrile lead 1 (light grey), and the corresponding methyl ester 22 (white) docked into, featuring: 1 hydrogen-bond acceptor (HBA) colored green, 2 hydrophobes depicted in cyan, and 1 double-bond feature in orange. The model has a correlation of $77.1 \%$ (max. fit 7.97, total cost 68.9, RMS 1.87) and was generated with the Discovery Studio 18.1.100.18065 software package $^{[29]}$ using a training set comprising of Rosacetol (7), Peonile (8), and Petalia (9) as well as compounds 1, 19, 20, 23, 26, 27, 28, 29, and 30 (uncert $=3$, conformational space $=20 \mathrm{kcal} / \mathrm{mol}$ ).

The model thus obtained features a correlation value of $77.1 \%$ and predicts competition between the nitrile group and the methyl ketone for the hydrogen bond acceptor site (green, Fig. 8). Ketonitrile $\mathbf{1}$ is suggested to bind via the carbonyl function, while the nitrile group points towards the double bond feature. Methyl ester 22, however, is predicted to bind via the nitrile moiety with the ester function occupying a hydrophobic space. The competing binding modes in this model are close in energy, while the hydrophobic substituents occupy hydrophobic pockets (cyan). The fit in the double bond feature (orange) might decide which hydrogen bond acceptor interacts with the receptors.

The olfactophore model in Fig. 8 serves mainly an illustrative purpose. The implication of excluded volume did not improve the fit, and thus the inactive compounds 19, 29, and $\mathbf{3 0}$ are not sterically penalized. However, the calculated activities are shown in Table 1.

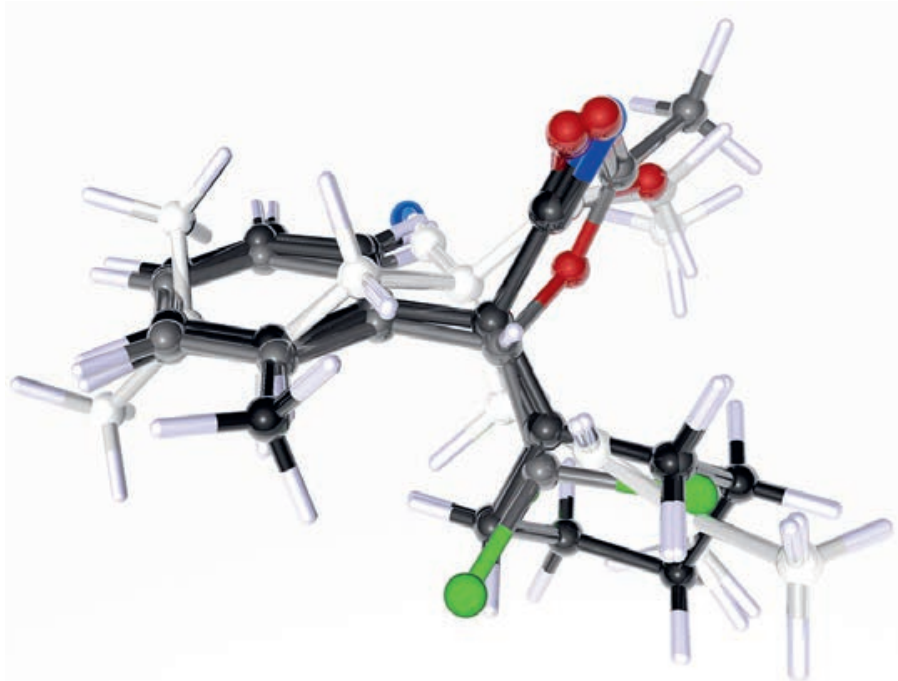

Fig. 9. Multiflexible alignment of Petalia (9, black), Peonile (8, dark grey), Rosacetol (7, grey), lead structure 1 (light grey), and the corresponding methyl ester 23 (white) with the MOE 2016.08.02 software package. ${ }^{[30]}$ The strain energy induced by this superposition has a value $U=16.4$ $\mathrm{kcal} / \mathrm{mol}$, its feature overlap as a measure of configurational similarity is $F=-95.0$, while the resulting alignment score of the probability-density overlap is $S=-78.6$.

In contrast, superposition analysis of Peonile (8), Petalia (9) and Rosacetol (7) with our lead compound $\mathbf{1}$ and methyl ester 23 by P. Kraft with the MOE 2016.08.02 software ${ }^{[30]}$ using an Amber10: Extended Hückel Theory (EHT) forcefield suggests that the nitrile groups of both methyl ester and methyl ketone point away from the ones in Peonile (8) and Petalia (9, Fig. 9). This analysis thus implies that the carbonyl moieties act as osmophoric groups. Taking both analyses into account, it remains unclear which of the two polar groups in bifunctional 1 and 23 undergoes hydrogen bonding with the receptor, while in the case of methylene analog $\mathbf{2 0}$ it must be the nitrile group.

This finding might explain the sensitivity differences among the panelists. If the olfactory receptors interacting with the nitrile odorants from this study feature slight structural variations in the binding pocket as a function of the genome, this could bias the bifunctional odorant to undergo hydrogen bonding interaction with either the carbonyl function or the nitrile moiety.

Table 1. Overview of the threshold data (hyperosmics in the case of different sensitivity groups) ${ }^{a}$

\begin{tabular}{|c|c|c|c|}
\hline Compound & Odor threshold [ng/L] & Experimental activity [pM] & Calculated activity [pM] \\
\hline Rosacetol (7) & 0.23 (rosy) & 0.86 (active) & 68 (moderate) \\
\hline Peonile $\mathbf{( 8 )}$ & 0.6 (rosy) & 0.52 (active) & 0.96 (active) \\
\hline Petalia (9) & 0.11 (rosy) & 0.51 (active) & 0.63 (active) \\
\hline $\mathbf{1}$ & 0.25 (freesia) & 1.1 (active) & 41 (moderate) \\
\hline $\mathbf{1 9}$ & 500 (vague) & 2100 (inactive) & 12 (active) \\
\hline $\mathbf{2 0}$ & 0.4 (rosy) & 1.8 (active) & 3.3 (active) \\
\hline $\mathbf{2 4}$ & 0.38 (rosy) & 1.6 (active) & 13 (active) \\
\hline $\mathbf{2 6}$ & 3.8 (rosy) & 19 (moderate) & 1.4 (active) \\
\hline $\mathbf{2 7}$ & 25 (green) & 120 (moderate) & 32 (moderate) \\
\hline $\mathbf{2 8}$ & 8.3 (floral) & 33 (moderate) & 33 (moderate) \\
\hline $\mathbf{2 9}$ & 500 (vague) & 2800 (inactive) & 1500 (active) \\
\hline
\end{tabular}

${ }^{a}$ For the compounds synthesized and considered in the generation of the model as well as a comparison of the measured experimental activities $[\mathrm{pM}]$ with the activities calculated by the Discovery Studio software ${ }^{[29]}$ for the olfactophore model in Fig. 8. 


\section{Conclusion and Outlook}

When working on a total synthesis, the path to success is a treacherous one. The outcome of a total synthesis endeavor is decided at the last step, since even seemingly simple functional group interconversions or deprotections can be extremely difficult in complex settings. Despite the need for perseverance and focus, it is important to be attentive regarding unexpected findings. Many groundbreaking discoveries arose by serendipity, that is by carefully analyzing and investigating unexpected observations. Without forfeiting determination and focus, in the case of our serendipitous finding it was worth to stop for an instant and smell the roses.

\section{Acknowledgements}

N.H. gratefully acknowledges Metrohm for the generous award. We would like to thank Sarah S. Eichenberger for her experimental contribution to this work. Katarina Grman, Sandro Dossenbach, Daniel Bieri, and their panelists are gratefully acknowledged for the determination of odor thresholds, and Dominique Lelievre for the olfactory evaluations.

Received: February 14, 2020

[1] C. H. Heathcock, in 'Chemical Synthesis: Gnosis to Prognosis', Eds.: C. Chatgilialoglu, V. Snieckus, Springer Netherlands, Dordrecht, 1996, pp. 223-243.

[2] R. B. Woodward, M. P. Cava, W. D. Ollis, A. Hunger, H. U. Daeniker, K. Schenker, Tetrahedron 1963, 19, 247.

[3] For recent examples see: a) M. Hönig, E. M. Carreira, Angew. Chem. Int. Ed. 2020, 59, 1192; b) P. Sondermann, E. M. Carreira, J. Am. Chem. Soc. 2019, 141, 10510; c) M. Brandstätter, M. Freis, N. Huwyler, E. M. Carreira, Angew. Chem. Int. Ed. 2019, 58, 2490; d) M. J. R. Richter, M. Schneider, M. Brandstätter, S. Krautwald, E. M. Carreira, J. Am. Chem. Soc. 2018, 140 16704; e) A. G. Kravina, E. M. Carreira, Angew. Chem. Int. Ed. 2018, 57, 13159; f) L. J. Nannini, S. J. Nemat, E. M. Carreira, Angew. Chem. Int. Ed. 2018, 130, 831; g) A. Shemet, E. M. Carreira, Org. Lett. 2017, 19, 5529; h) H. Wolleb, E. M. Carreira, Angew. Chem. Int. Ed. 2017, 56, 10890; i) C. Ebner, E.M. Carreira, Angew. Chem. Int. Ed. 2015, 54, 11227; j) S. A. Ruider, T. Sandmeier, E. M. Carreira, Angew. Chem. Int. Ed. 2015, 54, 2378 k) O. F. Jeker, A. G. Kravina, E. M. Carreira, Angew. Chem. Int. Ed. 2013, 52, 12166; 1) S. Breitler, E. M. Carreira, Angew. Chem. Int. Ed. 2013, 52 , 11168; m) S. Diethelm, E. M. Carreira, J. Am. Chem. Soc. 2013, 135, 8500; n) O. F. Jeker, E. M. Carreira, Angew. Chem. Int. Ed. 2012, 51, 3474; o) N. Huwyler, E. M. Carreira, Angew. Chem. Int. Ed. 2012, 51, 13066; p) L. M. Kreis, E. M. Carreira, Angew. Chem. Int. Ed. 2012, 51, 3436; q) M. E. Weiss, E. M. Carreira, Angew. Chem. Int. Ed. 2011, 50, 11501; r) C. M. Gampe, E. M. Carreira, Angew. Chem. Int. Ed. 2011, 50, 2962; s) C. S. Schindler, L. Bertschi, E. M. Carreira, Angew. Chem. Int. Ed. 2010, 49, 9229.

[4] For recent examples see: a) J. Boshkow, S. Fischer, A. M. Bailey, S. Wolfrum, E. M. Carreira, Chem. Sci. 2017, 8, 6904; b) S. Fischer, N. Huwyler, S Wolfrum, E. M. Carreira, Angew. Chem. Int. Ed. 2016, 55, 2555; c) A. M. Bailey, S. Wolfrum, E. M. Carreira, Angew. Chem. Int. Ed. 2016, 55, 639; d) J. Egger, P. Bretscher, S. Freigang, M. Kopf, E. M. Carreira, Angew. Chem. Int. Ed. 2013, 52, 5382; e) F. Kleinbeck, E. M. Carreira, Angew. Chem. Int $E d .2009,48,578$; f) A. M. Szpilman, D. M. Cereghetti, J. M. Manthorpe, N. R. Wurtz, E. M. Carreira, Chem. Eur. J. 2009, 15, 7117; g) A. M. Szpilman, J. M. Manthorpe, E. M. Carreira, Angew. Chem. Int. Ed. 2008, 47, 4339; h) A. M. Szpilman, D. M. Cereghetti, N. R. Wurtz, J. M. Manthorpe, E. M. Carreira, Angew. Chem. Int. Ed. 2008, 47, 4335.
[5] N. Hauser, P. Kraft, E. M. Carreira, Synthesis 2018, 50, 4490.

[6] V. Prelog, L. Ruzicka, P. Wieland, Helv. Chim. Acta 1944, 27, 66.

[7] V. Prelog, L. Ruzicka, P. Meister, P. Wieland, Helv. Chim. Acta 1945, 28, 618.

[8] A. Keller, H. Zhuang, Q. Chi, L. B. Vosshall, H. Matsunami, Nature 2007, $449,468$.

[9] A. Comfort, Nature 1971, 230, 432.

[10] a) G. Ohloff, W. Pickenhagen, P. Kraft, 'Scent and Chemistry: The Molecular World of Odors', Verlag Helvetica Chimica Acta, Zürich, Switzerland, 2012; b) K. J. Rossiter, Chem. Rev. 1996, 96, 3201.

[11] a) E. H. Polak, J. Theor. Biol. 1973, 40, 469; b) B. Malnic, J. Hirono, T. Sato, L. B. Buck, Cell 1999, 96, 713 .

[12] H. Boelens, J. Heydel, Chem. Ztg. 1973, 97, 8.

[13] J. Jozitsch, Zh. Russ. Fiz.-Khim. O-va 1897, 111

[14] T. Schmidt, W. Draber, W. Behrenz, DE 2644590, 1978

[15] M. Pesaro, WO 9716512, 1997.

[16] F. Flachsmann, J.-P. Bachmann, WO 2006133592, 2006.

[17] a) A. P. S. Narula, Chemistry \& Biodiversity 2004, 1, 1992; b) A. P. S. Narula, in 'Perspectives in Flavor and Fragrance Research', Eds.: P. Kraft, K. A. D. Swift, Verlag Helvetica Chimica Acta AG, Zürich, 2005, pp. 163-171.

[18] G. Ohloff, W. Giersch, Helv. Chim. Acta 1980, 63, 76.

[19] C. Sell, in 'The Chemistry of Fragrances', Eds.: D. H. Pybus, C. S. Sell, The Royal Society of Chemistry, 1999, pp. 51-124.

[20] A. Baur, Ber. 1891, 24, 2832.

[21] A. Baur-Thurgau, Ber. 1898, 31, 1344.

[22] D. Helmlinger, M. Pesaro, EP 115274, 1983

[23] M. Klaus, D. Helmlinger, M. Pesaro, EP 116277, 1983.

[24] P. Frankhauser, P. Fantini, EP 424787, 1989.

[25] a) J. Becker, G. Ohloff, Helv. Chim. Acta 1971, 54, 2889; b) J. J. Becker, DE 2026056, 1969; c) R. Hopp, K. Bauer, DE 2136496, 1971; d) R. Hopp, H. Finkelmeier, O. Koch, A. Körber, EP 512348, 1991.

[26] a) M. E. Welsch, S. A. Snyder, B. R. Stockwell, Curr. Opin. Chem. Biol. 2010, 14, 347; b) P. Schneider, G. Schneider, Angew. Chem. Int. Ed. 2017, $56,7971$.

[27] M. A. Fischbach, C. T. Walsh, Science 2009, 325, 1089.

[28] W. Sturm, Parfuem. Kosmet. 1974, 55, 351.

[29] Discovery Studio, v. 18.1.100.18065, Dassault Systèmes Biovia Corp., San Diego, CA 92121 USA, 2017. For more information, see http://accelrys. com/products/collaborative-science/biovia-discovery-studio/.

[30] Molecular Operating Environment (MOE), release 2016.08.02, Chemical Computing Group, Montreal, Quebec, Canada H3A 2R7, 2014. For more information, see http://www.chemcomp.com/.

\section{License and Terms}

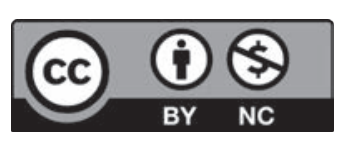

This is an Open Access article under the terms of the Creative Commons Attribution License CC BY_NC 4.0. The material may not be used for commercial purposes.

The license is subject to the CHIMIA terms and conditions: (http:// chimia.ch/component/sppagebuilder/?view=page \&id=12).

The definitive version of this article is the electronic one that can be found at doi:10.2533/chimia.2020.247 